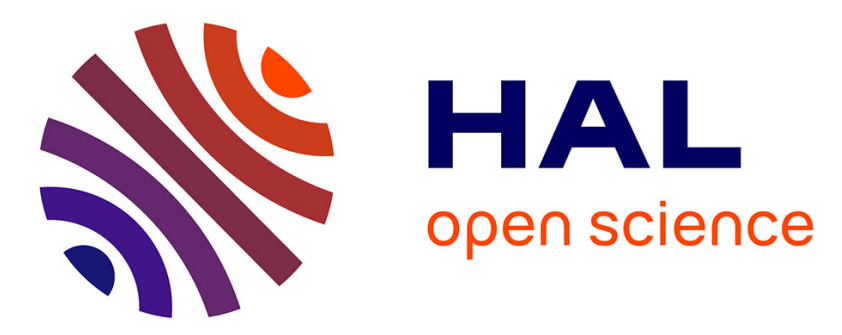

\title{
Improved single-chain-magnet behavior in a biradical-based nitronyl nitroxide-Cu-Dy chain
}

Jing Xie, Hong-Dao Li, Meng Yang, Juan Sun, Li-Cun Li, Jean-Pascal Sutter

\section{To cite this version:}

Jing Xie, Hong-Dao Li, Meng Yang, Juan Sun, Li-Cun Li, et al.. Improved single-chain-magnet behavior in a biradical-based nitronyl nitroxide-Cu-Dy chain. Chemical Communications, 2019, 55 (23), pp.3398-3401. 10.1039/C9CC00570F . hal-02140754

\section{HAL Id: hal-02140754 \\ https://hal.science/hal-02140754}

Submitted on 10 Nov 2020

HAL is a multi-disciplinary open access archive for the deposit and dissemination of scientific research documents, whether they are published or not. The documents may come from teaching and research institutions in France or abroad, or from public or private research centers.
L'archive ouverte pluridisciplinaire HAL, est destinée au dépôt et à la diffusion de documents scientifiques de niveau recherche, publiés ou non, émanant des établissements d'enseignement et de recherche français ou étrangers, des laboratoires publics ou privés. 


\title{
Improved single-chain-magnet behavior in a biradical-based nitronyl nitroxide-Cu-Dy chain
}

\author{
Jing Xie, ${ }^{a}$ Hong-Dao Li, ${ }^{a}$ Meng Yang, ${ }^{a}$ Juan Sun, ${ }^{a}$ Li-Cun Li, ${ }^{* a}$ and Jean-Pascal Sutter ${ }^{* b}$
}

\author{
${ }^{a}$ Department of Chemistry, Key Laboratory of Advanced Energy Materials Chemistry, College of \\ Chemistry, Nankai University, Tianjin 300071, China \\ E-mail: Ilicun@nankai.edu.cn \\ ${ }^{\mathrm{b}}$ LCC-CNRS, Université de Toulouse, Toulouse, France \\ E-mail: sutter@Icc-toulouse.fr
}

\section{Abstract :}

A biradical with ferromagnetic intramolecular interaction was found to improve the SCM behavior of a nitronyl nitroxideCu-Dy chain, resulting in an energy barrier for magnetization reversal of $40 \mathrm{~K}$.

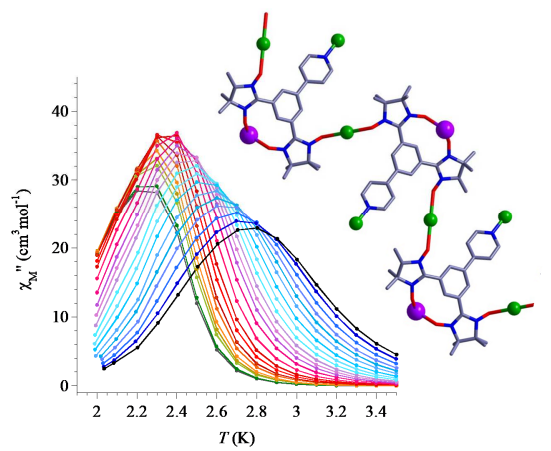

One-dimensional (1D) heterometallic coordination polymers represent an intriguing family of molecular magnetic compounds. A seminal example was reported by Kahn et al. ${ }^{1}$ and since then this design strategy has remained a flourishing research topic. ${ }^{2} A$ current focus concerns 1D compounds exhibiting slow magnetic relaxation of molecular origin known as single-chain magnets (SCM), ${ }^{3}$ and numerous heterometallic SCMs involving various metal combinations (for instance $3 d-3 d^{\prime},{ }^{4} \quad 3 d-4 d,{ }^{5} \quad 3 d-5 d,{ }^{6} \quad 3 d-4 f,{ }^{7}$ and even heterotrimetallic ${ }^{8}$ ) have been reported. ${ }^{9}$ For SCMs, the correlation energy contributes to the 
energy barrier for magnetization reversal, ${ }^{11}$ therefore strong exchange interactions within the chains are desirable for increasing the blocking temperature. This latter represents a crucial synthetic challenge for rising the energy barrier of SCMs. ${ }^{12}$ A promising strategy consists in using organic radicals as bridging ligands in order to shorten the distance between the magnetic centers and achieve largest possible magnetic communication along the 1D array. ${ }^{2 c, 13}$ This is obtained when an organic radical unit directly coordinates two consecutive metal centers. Several remarkable SCMs based on this approach have been reported, involving either $3 \mathrm{~d}$ or $4 \mathrm{f}$ metal ions, ${ }^{14,15}$ and such metal-radical systems have been demonstrated to be photoswitchable and compatible with observation of magneto-optical properties. ${ }^{10}$ Related $2 \mathrm{p}-3 \mathrm{~d}-4 \mathrm{f}$ SCMs (i.e. hetero-tri-spin compounds) were hardly investigated, ${ }^{16,17}$ however they provide new opportunities for fine-tuning the magnetic couplings between spins, the ligand field, and magnetic anisotropy of the metal centers.

Our contribution to this topic concerns nitronyl nitroxide radical-3d-4f derivatives, ${ }^{17}$ in particular ferromagnetic chains with this radical unit acting as a bridge between the metal ions. ${ }^{18}$ Slow magnetic relaxation have been observed when anisotropic $\mathrm{Ln}$ ions were involved but SCM characteristics remained modest. A likely cause is the antiferromagnetic nextneighbour radical-radical interaction via the Ln centers, ${ }^{18 b, 19}$ a contribution of similar amplitude but opposite to the ferromagnetic radical-Ln interactions resulting in a situation similar to spin frustration. We conjectured that the effect of this competitive contribution could be reduced by an additionnal ferromagnetic exchange pathway between radicals, a feature easily implemented in biradicals. ${ }^{20}$ This is confirmed herein by a hetero-tri-spin SCM constructed using the nitronyl nitroxide (NIT hereafter) biradical, bisNITPhPy (i.e. [5-(4pyridyl)-1,3-bis(1'-oxyl-3'-oxido-4', 4',5',5'-tetramethyl-4,5-hydro-1H-imidazol-2-yl)]benzene), with meta-positioned radical moieties.

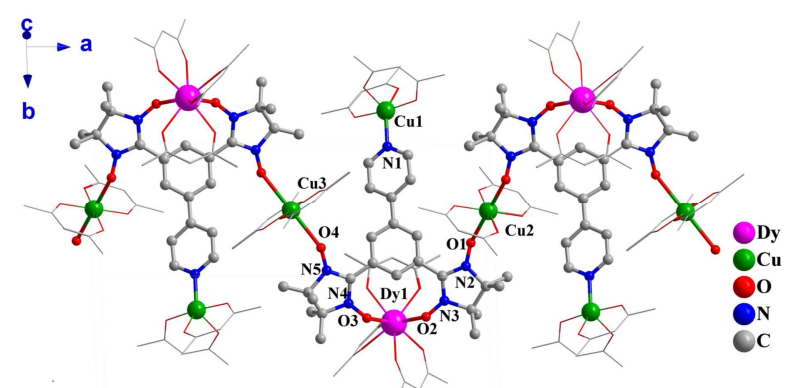

Figure 1. One-dimensional structure of complex 1. All hydrogen and fluorine atoms are omitted for clarity.

The 1D coordination polymer $\left[\mathrm{DyCu}_{2}(\mathrm{hfac})_{7}(\right.$ bisNITPhPy) 1 was obtained as dark-green single crystals from the one-pot reaction between $\mathrm{Dy}(\mathrm{hfac})_{3} \cdot 2 \mathrm{H}_{2} \mathrm{O}, \mathrm{Cu}(\mathrm{hfac})_{2}$ and bisNITPhPy with a mole ratio of 1:2:1 in a $n$-hexane- $\mathrm{CHCl}_{3}$ mixture (see ESI). Single crystal X-ray analysis 
revealed that $\mathbf{1}$ has one-dimensional chain structure consisting in an alternation of $\mathrm{Cu}(\mathrm{II})$ and Dy(III) ions bridged by NIT units (Fig. 1). This arrangement is made up by one bisNITPhPy, one Dy(hfac $)_{3}$, and two $\mathrm{Cu}(\mathrm{hfac})_{2}$ units. The organic ligand and the Dy form a chelate resulting from coordination of one aminoxyl (NO) moiety of each NIT to a central Dy, while the second NOs are coordinated to one $\mathrm{Cu}(\mathrm{II})$ each. The ligand is further linked to one independent and terminal $\mathrm{Cu}(\mathrm{hfac})_{2}$ by the means of the pyridyl group. The Dy ion is ligated by six oxygen atoms from three bidentate hfac anions and two nitroxide groups forming a biaugmented trigonal prism $\left(C_{2 v}\right)^{21}$ coordination polyhedron (Table S3). The Dy- $\mathrm{O}_{\text {rad }}$ distances are 2.368(5) $\AA$ and 2.385(5) $\AA$, respectively, and the $\mathrm{Dy}-\mathrm{O}_{\mathrm{hfac}}$ bond lengths fall within the range of 2.298(5)-2.375(5) $\AA$ (Table S2 in ESI). The O(rad)-Dy-O(rad) angle is $82.4(7)^{\circ}$ and the dihedral angles between the ON-C-NO fragment and the phenyl ring of biradical unit are $29.75(9)^{\circ}$ and $29.02(1)^{\circ}$, respectively. The $\mathrm{Cu}$ units linked to the NIT moieties are crystallographically independent and appear as Cu2 and Cu3 in Fig. 1. They exhibit an elongated octahedral coordination environment formed by four $\mathrm{O}$ atoms from hfac ligands located in the equatorial positions, and two $\mathrm{O}$ atoms from two bisNITPhPy ligands in the apical positions. The $\mathrm{Cu}-\mathrm{O}(\mathrm{hfac})$ bond lengths vary from $1.922(5) \AA$ to $1.938(6) \AA$ and the $\mathrm{Cu}$ $\mathrm{O}_{\text {rad }}$ bond distances are 2.388(6) $\AA$ for Cu2 and 2.604(6) $\AA$ for Cu3. The pyridyl-coordinated $\mathrm{Cu} 1$ has a distorted pyramidal geometry consisting of four $\mathrm{O}$ atoms from two hfac and one $\mathrm{N}$ atom from pyridine, in which the axial position is occupied by one $\mathrm{O}$ atom (Cu1-05:

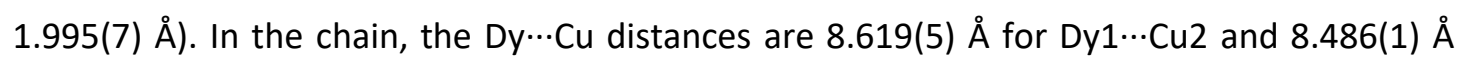

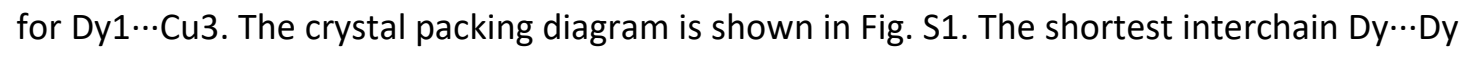
separation is 10.013(8) $\AA$ and the nearest Dy...Cu distance between the chains is $10.310(8) \AA$.

The temperature dependence of the magnetic susceptibility, $\chi_{M}$ (given for a bisNITPhPyDyCu $\mathrm{C}_{2}$ moiety) for 1 has been investigated between 2 and $300 \mathrm{~K}$, and the results are plotted as $\chi_{M} T=f(T)$ in Fig. 2 (see also Fig. S4 in ESI). The phase purity of the sample was confirmed by PXRD (Fig. S3). The value found at $300 \mathrm{~K}$ for $\chi_{M} T$ is $16.15 \mathrm{~cm}^{3} \mathrm{~K} \mathrm{~mol}^{-1}$, slightly above the Curie contribution of $15.67 \mathrm{~cm}^{3} \mathrm{~K} \mathrm{~mol}^{-1}$ expected for one Dy ${ }^{\prime \prime \prime}$ ion $\left({ }^{6} \mathrm{H}_{15 / 2}, 14.17\right.$ $\left.\mathrm{cm}^{3} \mathrm{~mol}^{-1} \mathrm{~K}\right)$, two $\mathrm{Cu}^{\prime \prime}(S=1 / 2, \mathrm{~g}=2.0)$ and two organic radicals $(S=1 / 2)$ in the absence of exchange interactions. The $\chi_{M} T$ product increases smoothly as $T$ is reduced and below $20 \mathrm{~K}$ it rises rapidly and reaches $313 \mathrm{~cm}^{3} \mathrm{~K} \mathrm{~mol}^{-1}$ for $2 \mathrm{~K}$. Such a behaviour is characteristic for longrange magnetic correlation without magnetic ordering, in agreement with the expected behaviour for a spin chain. The field dependence of the magnetization recorded at $2 \mathrm{~K}$ is characterized by a very sharp increase for small fields followed by a smoother but steady increase to reach $8.5 \mu \mathrm{B}$ with $50 \mathrm{kOe}$. A similar behaviour was found for 3,4 , and $5 \mathrm{~K}$ (Fig. 2 and S5). The magnetisation reached for the largest investigated field suggests dominant ferromagnetic interactions within the chain, in agreement with the $\chi_{M} T=f(T)$ behaviour. 


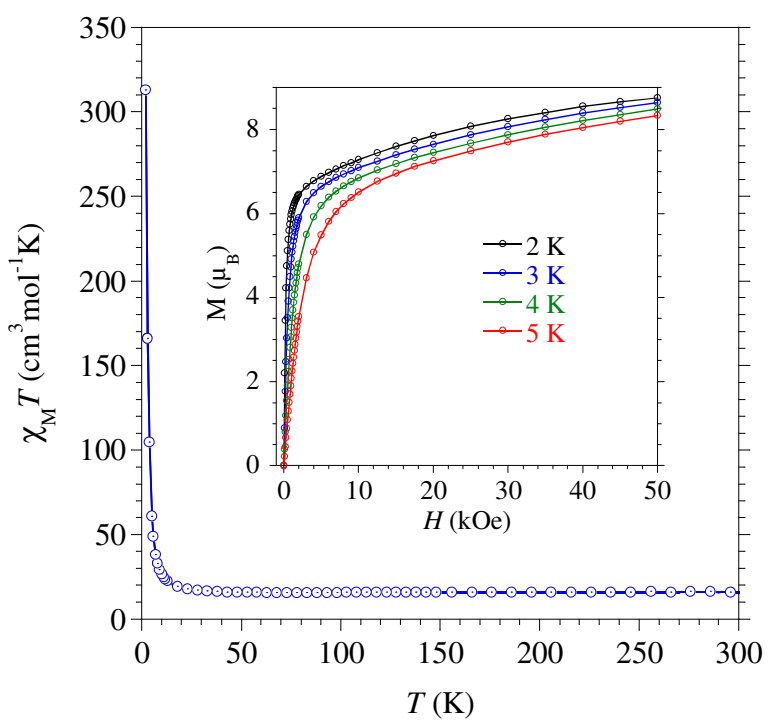

Figure 2. $\chi_{M} T$ versus $T$ behavior for 1 (data from 300 to $100 \mathrm{~K}$ have been collected in an applied field of $1 \mathrm{kOe}$ and those below with $H=50$ Oe to avoid saturation (see Fig. SI4); the inset shows the field dependence of the magnetization at 2, 3, 4, and $5 \mathrm{~K}$.

This is consistent with the anticipated behaviour for the present system. Indeed, the axial coordination of aminoxyl groups to the $\mathrm{Cu}(\mathrm{II})$ ions are expected to lead to ferromagnetic $\mathrm{Cu}$ radical interactions due to orthogonality of the magnetic orbital $\left(d x^{2}-y^{2}\right)$ on copper and $\pi^{*}$ SOMO on the radical, ${ }^{22}$ and the Dy-nitronyl nitroxide exchange interaction is also anticipated to be ferromagnetic; ${ }^{23}$ moreover ferromagnetic intra-ligand radical-radical interaction is also expected. $^{24}$

For $1, \ln \left(\chi_{M}^{\prime} T\right)=f\left(T^{1}\right)\left(\chi_{M}^{\prime}\right.$, the in-phase AC susceptibility in the absence of dc field) shows a linear region between 3.0 and $25 \mathrm{~K}$ (Fig. S4) that leads to a correlation energy of $\Delta_{\xi} / \mathrm{k}_{\mathrm{B}}=7.7 \mathrm{~K}$ $\left(5.3 \mathrm{~cm}^{-1}\right)$ and $C_{\text {eff }}=12.6 \mathrm{~cm}^{3} \mathrm{~mol}^{-1} \mathrm{~K}$, thus confirming the $1 \mathrm{D}$ Ising-like character of 1 .

AC susceptibilities, measured in the absence of a static field, showed frequency dependent $\chi_{M}{ }^{\prime}$ and $\chi_{M}{ }^{\prime \prime}$ behaviors (Fig. 3), a typical feature associated with slow magnetic relaxation. The analysis of the Cole-Cole plots, $\chi_{M}{ }^{\prime \prime}=f\left(\chi_{M}{ }^{\prime}\right)$, gave a distribution width for the relation times of $\alpha=0.11$ to 0.37 between 2 and $3 \mathrm{~K}$. Such a distribution might be indicative for a population of chains of different lengths, however this was not detected when analysing the relaxation times (vide infra). 

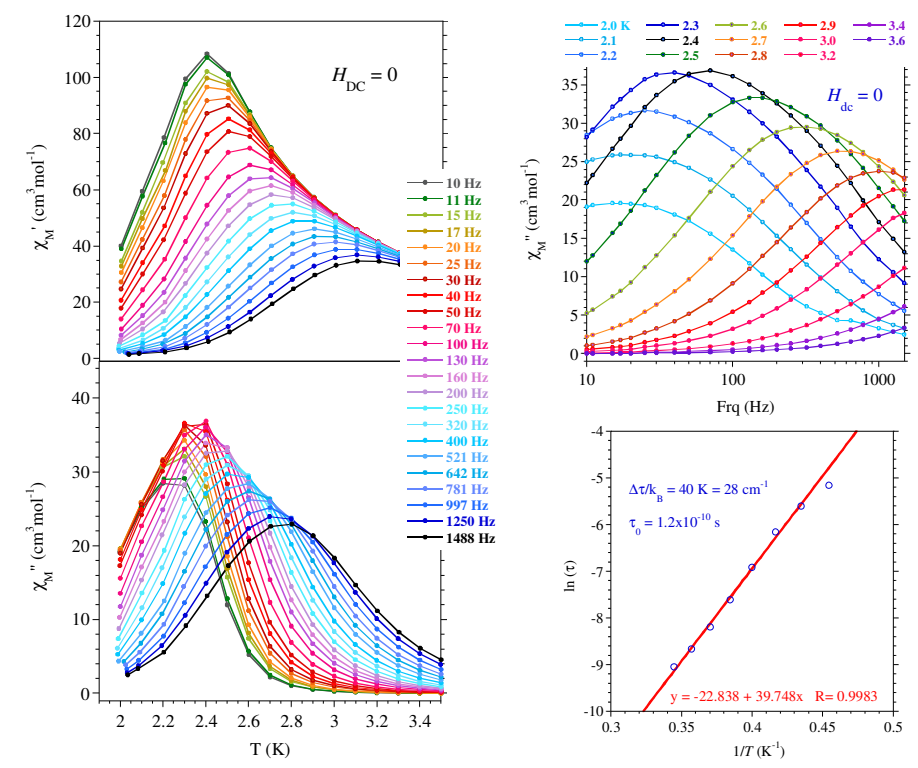

Figure 3. (left) $\chi_{M}{ }^{\prime}$ and $\chi_{M}{ }^{\prime \prime}=f(T)$ for frequencies between 10 and $1488 \mathrm{~Hz}$ obtained in zero field; (right) $\chi_{M}{ }^{\prime \prime}=f(F r q)$ for temperatures between 2 and $3.6 \mathrm{~K}$, and $\ln (\tau)=f\left(\mathrm{~T}^{-1}\right)$ with best fit (red line) to Arrhenium equation.

The relaxation times $(\tau)$ between 2.2 and $3.0 \mathrm{~K}$ were deduced from $\chi_{M}{ }^{\prime \prime}=f(v)$ behaviors using the Debye model, ${ }^{25}$ and subsequently fitted by the Arrhenius law $\left[\tau=\tau_{0} \exp \left(\Delta_{\tau} / k_{B} T\right)\right]$ to afford an energy barrier of $40.0 \mathrm{~K}$ with a pre-exponential factor $\left(\tau_{0}\right)$ of $1.2 \times 10^{-10} \mathrm{~s}$. In SCM, the variation of $\tau$ with $T$ often exhibits a crossover between two thermally activated modes related to the occurrence of finite- and infinite-size regimes in the relaxation process. ${ }^{11}$ This is not observed here, likely due to the small Ln-radical exchange interactions in $\mathbf{1}$ and the narrow temperature window for wich $\tau$ could be assessed. The above energy barrier, $\Delta_{\tau}$, comprises two contributions which are the correlation energy $\Delta_{\xi}$, and the blocking energy due to the magnetic anisotropy of the elementary magnetic unit, $\Delta_{\mathrm{A}} \cdot{ }^{11}$ For 1 , supposing finite-size chains, this latter contribution is in the order of $\Delta_{\mathrm{A}}=23 \mathrm{~cm}^{-1}(32 \mathrm{~K})$ from the difference between $\Delta_{\tau}$ and $\Delta_{\xi}$.

The magnetic characteristics exhibited by 1 are clearly improved compared to related $2 p-3 d-$ $4 \mathrm{f}$ chain compounds ${ }^{18}$ and this supports our assumptions and strategy disclosed herein. The effective role of the biradical species promoting a ferromagnetic NIT-NIT interaction and thus limiting the next-neighbour contribution needs to be confirmed but the present results show that such biradicals provides promissing opportunities to develop SCM with appealing properties.

This work was financially supported by the National Key R\&D Program of China (2018YFA0306002) and the National Natural Science Foundation of China (No. 21773122 and 21471083). 


\section{References}

1 O. Kahn, Y. Pei, M. Verdaguer, J. P.Renard, J. Sletten. J. Am. Chem. Soc., 1988, 110, 782.

2 (a) M. Verdaguer, A. Bleuzen, V. Marvaud, J. Vaissermann, M. Seuleiman, C. Desplanches, A. Scuiller, C. Train, R. Garde, G. Gelly, C. Lomenech, I. Rosenman, P. Veillet, C. Cartier and F. Villain, Coord. Chem. Rev., 1999, 190-192, 1023; (b) J. S. Miller, Chem. Soc. Rev., 2011, 40, 3266; (c) L. Bogani, A. Vindigni, R. Sessoli, D. Gatteschi, J. Mater. Chem., 2008, 18, 4750; (d) H. L. Sun, Z. M. Wang, S. Gao, Coord. Chem. Rev., 2010, 254, 1081; (e) S. Turner, 0. Kahn, L. Rabardel, J. Am. Chem. Soc., 1996, 118, 6428; (f) K. S. Pedersen, J. Bendix, R. Clérac, Chem. Commun., 2014, 50, 4396. (g)M. Andruh, Chem. Commun.,2018, 54, 3559.

3 A. Caneschi, D. Gatteschi, N. Lalioti, C. Sangregorio, R. Sessoli, G.Venturi, A. Vindigni, A. Rettori, M. G. Pini, M. A. Novak. Angew. Chem. Int. Ed., 2001, 40, 1760.

4 (a) R. Clérac, H. Miyasaka, M. Yamashita and C. Coulon, J. Am. Chem. Soc., 2002, 124, 12837; (b) S. Wang, J.-L. Zuo, S. Gao, Y. Song, H.C. Zhou, Y. Z. Zhang, X. Z. You, J. Am. Chem. Soc., 2004, 126, 8900; (c) E. Coronado, J. R. Galán-Mascarós and C. Mart? Gastaldo, J. Am. Chem. Soc., 2008, 130, 14987; (d) H. R. Wen, Y. Z. Tang, C. M. Liu, J. L. Chen, C. L. Yu, Inorg. Chem., 2009, 48, 10177; (e) E. Pardo, C. Train, R. Lescouezec, Y. Journaux, J. Pasán, C. R. Pérez, F. S. Delgado, R. R.Garcia, F. Lloret, C. Paulsen, Chem. Commun., 2010, 46, 2322; (f) Y. Q. Wang, Q. Yue, E. Q. Gao, Chem. Eur. J., 2017, 23, 896; (g) X. B. Li, Y. Ma, E. Q. Gao, Inorg. Chem., 2018, 57, 7446. (h) C. Pichon, N. Suaud, C. Duhayon, N. Guihéry, J.-P. Sutter, J. Am. Chem. Soc. 2018, 140, 7698.

5 (a) J. F. Guo, X. T. Wang, B.W. Wang, G. C. Xu, S. Gao, L. Szeto, W.T. Wong, W.Y. Wong, T.C. Lau, Chem. Eur. J., 2010, 16, 3524; (b) D. P. Zhang, L. F. Zhang, Y. T. Chen, H. L. Wang, Z. H. Ni, W. Wernsdorferc , J. Z. Jiang, Chem. Commun., 2010, 46, 3550. (c) T. S. Venkatakrishnan, S. Sahoo, N. Bréfuel, C. Duhayon, C. Paulsen, A. L. Barra, S. Ramasesha, J. P. Sutter, J. Am. Chem. Soc., 2010, 132, 6047.

6 (a) S. W. Choi, H. Y. Kwak, J. H. Yoon, H. C. Kim, E. K. Koh, C. S. Hong, Inorg. Chem., 2008, 47, 10214; (b) X.W. Feng, T. D. Harris, J. R. Long, Chem. Sci., 2011, 2, 1688; (c) X.W. Feng, J. J. Liu, T. D. Harris, S. Hill, J. R. Long, J. Am. Chem. Soc., 2012, 134, 7521; (d) Y.Q. Zhang, C.L. Luo, X. B. Wu, B.W. Wang, S. Gao, Inorg. Chem., 2014, 53, 3503; (e) Y.Z. Zhang, B. S. Dolinar, S. H. Liu, A. J. Brown, X. Zhang, Z. X. Wanga, K. R. Dunbar, Chem. Sci., 2018, 9, 119. 7 (a) A. Figuerola, J. Ribas, D. Casanova, M. Maestro, S. Alvarez, C. Diaz, Inorg. Chem., 2005, 44, 6949; (c) M. X. Yao, Q. Zheng, K. Qian, Y. Song, Song Gao, J. L. Zuo, Chem. Eur. J., 2013, 19, 294; (d) A. Dey, S. Das, S. Kundu, A. Mondal, M. Rouzières, C. Mathonière, R. Clérac, R. S. Narayanan, V. Chandrasekhar, Inorg. Chem., 2017, 56, 14612

8 D. Visinescu, A. M. Madalan, M. Andruh, C. Duhayon, J.-P. Sutter, L. Ungur, W. Van den Heuvel, L. F. Chibotaru, Chem. Eur. J. 2009, 15, 11808.

9 (a) S. Dhers, H. L. C. Feltham, S. Brooker, Coord. Chem. Rev., 2015, 296, 24; (b) R. Lescouëzec, L. M. Toma, J. Vaissermann, M. Verdaguer, F. S. Delgado, C. Ruiz-Pérez, F. Lloret, M. Julve, Coord. Chem. Rev. 2005, 249, 2691.

10 (a) E. Heintze, F. El Hallak, C. Clauß, A. Rettori, M. G. Pini, F. Totti, M. Dressel, and L. Bogani, Nat. Mater., 2013, 12, 202; (b)R. Sessoli, M.-E. Boulon, A. Caneschi, M. Mannini, L. Poggini, F. Wilhelm, A. Rogalev, Nat Phys 2015, 11, 69-74.

11 C. Coulon, V. Pianet, M. Urdampilleta, R. Clérac, Struct. Bond., Vol. 164 (Ed.: S. Gao), Springer Berlin Heidelberg, 2015, pp. 143. 
12 (a) H. Miyasaka, M. Julve, M. Yamashita, R.Clérac, Inorg. Chem., 2009, 48, 3420; (b) W. X. Zhang, R. Ishikawa, B. Breedlove, M. Yamashita, RSC Adv., 2013, 3, 3772.

13 X. X. Meng, W. Shi, P. Cheng, Coord. Chem. Rev., 2019, 378, 134.

14 (a) H. Miyasaka, T. Madanbashi, K. Sugimoto, Y. Nakazawa, W. Wernsdorfer, K. Sugiura, M. Yamashita, C. Coulon, R. Clérac, Chem. Eur. J., 2006, 12, 7028; (b) N. Ishii, Y. Okamura,S. Chiba, T. Nogami, T. Ishida, J. Am. Chem. Soc. 2008, 130, 24; (c) M. Bałanda, Z. Tomkowicz, W. Haase, M. Rams, J. Phys. Conf. Ser., 2011, 303, 012036; (d) M. G. F. Vaz, R. A. A. Cassaro, H. Akpinar, J.A. Schlueter, P. M. Lahti, M.A. Novak, Chem. Eur. J., 2014, 20, 5460 ; (e)R. Ishikawa, K. Katoh, B. K. Breedlove, M. Yamashita, Inorg. Chem., 2012, 51, 9123; (f) R. A. A. Cassaro, S. G. Reis, T. S. Araujo, P. M. Lahti, M. A. Novak, M. G. F. Vaz, Inorg. Chem., 2015, 54, 9381.

15 (a) L. Bogani, C. Sangregorio, R. Sessoli, D. Gatteschi, Angew. Chem., Int. Ed., 2005, 44, 5817; (b) K. Bernot, L. Bogani, A. Caneschi, D. Gatteschi, R. Sessoli, J. Am. Chem. Soc., 2006, 128, 7947 ;(c)X. F. Wang, Y. G. Li, P. Hu, J. J. Wang , L. C. Li, Dalton Trans., 2015, 44, 4560. (d) R. N. Liu, L. C. Li, X. L. Wang, P. P.Yang, C. Wang, D.Z. Liao, J. P. Sutter, Chem. Commun., 2010, 46, 2566. (e) P. Hu, X. F. Wang, Y. Ma, Q. L. Wang, L.C. Li, D.Z. Liao, Dalton Trans., 2014, 43, 2234 ;(d) T. Han, W. Shi, Z. Niu, B. Na, P. Cheng, Chem. Eur. J., 2013, 19, 994.

16 Z. X. Wang, X. Zhang, Y. Z. Zhang, M. X. Li, H. H. Zhao, M. Andruh, K. R. Dunbar, Angew. Chem. Int. Ed., 2014, 53, 11567 .

17 M. Zhu, L. Li, J.-P. Sutter, Inorg. Chem. Front., 2016, 3, 994.

18 (a) M. Yang, J. Xie, Z. Sun, L.C. Li, J. P. Sutter, Inorg. Chem., 2017, 56, 13482; (b) M. Zhu, P. Hu, Y. G. Li, X. F. Wang, L. C. Li, D. Z. Liao, V. M. L. Durga Prasad Goli, S. Ramasesha, J. P. Sutter, Chem. Eur. J., 2014, 20, 13356; (c) X. F. Wang, P. Hu, L. C. Li, J. P. Sutter, Inorg. Chem., 2015, 54, 9664.

19 J. P. Sutter, M. L. Kahn, S. Golhen, L. Ouahab, O. Kahn, Chem. Eur. J. 1998, 4, 571.

20 (a)H. Iwamura, Pur. Appl. Chem. 1986, 58, 187. (b) L. Catala, J. L. Moigne, N. Kyritsakas, P. Rey, J. J. Novoa, P. Turek, Chem. Eur. J.,2001, 7, 2466.

21 (a) D. Casanova, M. Llunell, P. Alemany, S. Alvarez, Chem. Eur. J. 2005, 11, 1479. (b) Llunell, M. Casanova, D. Cirera, J. Alemany, P. Alvarez, S. SHAPE, 2.1 ed.; University of Barcelona: Barcelona, Spain, 2013.

22 (a) D. Gatteschi, J. Laugier, P. Rey, C. Zanchini, Inorg. Chem., 1987, 26, 938; (b) D. Luneau, P. Rey, J. Laugier, P. Fries, A. Caneschi, D. Gatteschi , R. Sessoli, J. Am. Chem. Soc., 1991, 113, 1245.

23 (a) M. L. Kahn, J. P. Sutter, S. Golhen. P. Guionneau, L. Ouahab, O. Kahn and D. Chasseau, J. Am. Chem. Soc., 2000, 122, 3413; (b) K. Bernot, F. Pointillart, P. Rosa, M. Etienne, R. Sessoli, D. Gatteschi, Chem. Commun., 2010, 46, 6458 .

24 D. Shiomi, M. Tamura, H. Sawa, R. Kato, M. Kinoshita, J.Phys. Soc. Jpn., 1993, 62, 289.

25 (a) S. M. J. Aubin, Z. Sun, L. Pardi, J. Krzystek, K. Folting, L. C. Brunel, A. L. Rheingold, G. Christou, D. N. Hendrickson, Inorg. Chem., 1999, 38, 5329; (b) C. Dekker, A. F. M. Arts, H. W. de Wijn, A. J. van Duyneveldt, J. A. Mydosh, Phys. Rev. B, 1989, 40, 11243. 


\section{SUPPORTING INFORMATION}

\section{CONTENTS}

\section{Experimental section}

1. Materials and physical measurements .

2. Synthesis.

3. X-ray crystallography....

Table S1. Crystallographic data and structure refinement parameters for 1.

Table S2. Selected bond lengths $[\AA]$ and angles $\left[{ }^{\circ}\right]$ for 1 .

Figure S1. Packing diagram of complex 1 . The coligand hfac- and all H, F atoms are omitted for clarity.

Figure S2. Coordination polyhedron of the $\mathrm{Dy}^{\prime \prime \prime}, \mathrm{Cu}^{\prime \prime} 1, \mathrm{Cu}^{\prime \prime} 2$ and $\mathrm{Cu}^{\prime \prime} 3$ ions.

Table S3. Detailed geometry analysis results by Continuous Shape Measures

Figure S3 Powder X-ray diffraction pattern of Dy complex at $293 \mathrm{~K}$, together with the calculated pattern from the crystal structure data.

\section{Magnetic Studies}

Figure S4. Temperature dependence of $\chi_{M} T$ with $\chi_{M}$ and $\ln \left(\chi_{M}{ }^{\prime} T\right)=f\left(T^{1}\right)$.

Figure S5. Field dependence of the magnetization at different temperatures for 1 .....

Figure S6. $\chi_{M}{ }^{\prime}=f\left(\chi_{M}{ }^{\prime \prime}\right)$.

Figure S7. Temperature and Frequency-dependent in-phase signals ( $\left.\chi^{\prime}\right)$ for $\mathbf{1}$ under zero dc field with $H_{\mathrm{AC}}=3$ Oe.

\section{References}




\section{Experimental section}

\section{Materials and Physical Measurements}

All reagents and solvents were purchased from commercial sources and used as received. The biradical ligand NITPhPybis was prepared according to literature method. ${ }^{[11]}$ Elemental analysis (for $\mathrm{C}, \mathrm{H}$, and $\mathrm{N}$ ) was implemented on a PerkinElmer 240 elemental analyzer. Infrared spectra were measured in the $4000-400 \mathrm{~cm}^{-1}$ range on $\mathrm{KBr}$ pellets using a Bruker TENOR 27 spectrometer. Magnetic measurements were performed on a Quantum Design MPMS 5 SQUID magnetometer using crystalline powder samples mixed to grease. Magnetic susceptibility data were corrected for the diamagnetic contribution of all the constituent atoms with Pascal's constants and the sample holder.

\section{Synthesis}

\section{$\left[\mathrm{DyCu}_{2}(\mathrm{hfac})_{7}(\mathrm{NITPhPybis})\right] 1$}

A mixture of $\mathrm{Dy}(\mathrm{hfac})_{3} \cdot 2 \mathrm{H}_{2} \mathrm{O}(0.01 \mathrm{mmol}, 0.0082 \mathrm{~g})$ and $\mathrm{Cu}(\mathrm{hfac})_{2}(0.02 \mathrm{mmol}, 0.009 \mathrm{~g})$ was dissolved in $15 \mathrm{~mL}$ dry boiling $n$-hexane. The solution was maintained to reflux for $6 \mathrm{~h}$, then cooled to $50{ }^{\circ} \mathrm{C}$ and NITPhPybis ligand $(0.01 \mathrm{mmol}, 0.0047 \mathrm{~g})$ in a $\mathrm{CHCl}_{3}$ solution $(6 \mathrm{~mL})$ was added to the above solution. The resulting solution was heated for $15 \mathrm{~min}$ and then was cooled to room temperature, filtered, and stored at room temperature for slow evaporation. After a week, dark-green strip crystals were obtained for single crystal X-ray analysis. Yield: 65\%. Calcd for $\mathrm{C}_{60} \mathrm{H}_{38} \mathrm{Cu}_{2} \mathrm{~F}_{42} \mathrm{DyN}_{5} \mathrm{O}_{18}$ (2204.56 $\mathrm{g} \mathrm{mol}^{-1}$ ): $\mathrm{C}, 32.69 ; \mathrm{H}, 1.72 ; \mathrm{N}, 3.18$. Found: $\mathrm{C}$, 32.67; H, 2.05; N, 3.25. FT-IR (KBr): 3417(m), 2877(m), 2432(m), 1789(m), 1653(s), 1533(s), 1477(s), 1360(s) , 1154(s), 1074(s), 949(s), 860(s), 662(s), 588(m), 547(s) $\mathrm{cm}^{-1}$.

\section{X-ray crystallography}

The crystal data were collected at $113 \mathrm{~K}$ on a Rigaku Saturn CCD diffractometer (Mo/K $\alpha$ radiation, $\lambda=0.71073 \AA$ ) . The multi-scan absorption corrections were conducted using the SADABS program. ${ }^{\left[{ }^{2}\right]}$ These structures were solved by direct methods and then refined by full-matrix least-squares on $F^{2}$ using crystallographic software package program SHELXS2014. ${ }^{[\mathrm{S3}]}$ Non-H atoms were refined anisotropically. All hydrogen atoms were set in calculated positions and refined as riding on the corresponding non-hydrogen atoms. Information concerning detailed crystallographic data collections and structure refinements parameters are provided in Table S1. Selected bond distances $(\AA)$ and angles $\left({ }^{\circ}\right)$ are shown in Table S2. Crystallographic data for the structural analyses have been deposited with the Cambridge Crystallographic Data Centre, CCDC 1879743 contain the supplementary crystallographic data for complex 1 . These information can be obtained free of charge via www.ccdc.cam.ac.uk/data request/cif.

Table S1. Crystallographic data and structure refinement parameters for 1. 


\begin{tabular}{|c|c|}
\hline Complexes & 1Dy \\
\hline Empirical formula & $\mathrm{C}_{60} \mathrm{H}_{38} \mathrm{Cu}_{2} \mathrm{~F}_{42} \mathrm{DyN}_{5} \mathrm{O}_{18}$ \\
\hline$M r$ & 2204.53 \\
\hline$T(\mathrm{~K})$ & 113 \\
\hline Crystal system & monoclinic \\
\hline Space group & $P 2 \sqrt{ } / c$ \\
\hline$a / \AA ̊$ & $20.944(4)$ \\
\hline$b / \AA ̊$ & $20.520(4)$ \\
\hline$c / \AA ̊$ & $19.008(4)$ \\
\hline$\alpha /^{\circ}$ & 90.000 \\
\hline$B /^{\circ}$ & $95.45(3)$ \\
\hline$y /^{\circ}$ & 90.000 \\
\hline$V / \AA^{3}$ & $8132(3)$ \\
\hline$Z$ & 4 \\
\hline$D_{\text {calcd }} / \mathrm{g} \mathrm{cm}^{-3}$ & 1.801 \\
\hline$\mu / \mathrm{mm}^{-1}$ & 1.590 \\
\hline$\vartheta /{ }^{\circ}$ & 1.816to 25.009 \\
\hline$F(000)$ & 4316 \\
\hline Collected reflections & 64162 \\
\hline Independent reflections & 14313 \\
\hline$R_{\text {int }}$ & 0.0749 \\
\hline $\mathrm{GOF}\left(\mathrm{F}^{2}\right)$ & 1.069 \\
\hline R1/wR2 $(I>2 \sigma(I))$ & $0.0806 / 0.2053$ \\
\hline R1/wR2 (all data) & $0.0997 / 0.2218$ \\
\hline
\end{tabular}


Table S2. Selected bond lengths $[\AA]$ and angles $\left[{ }^{\circ}\right]$ for $\mathbf{1}$.

\begin{tabular}{|c|c|c|c|}
\hline \multicolumn{4}{|l|}{ Bond distances } \\
\hline Dy(1)-O(2) & $2.367(5)$ & $\mathrm{Cu}(2)-\mathrm{O}(1)$ & $2.388(6)$ \\
\hline Dy (1)-O(3) & $2.385(5)$ & $\mathrm{Cu}(2)-\mathrm{O}(1) \# 1$ & $2.388(6)$ \\
\hline Dy (1)-O(13) & $2.347(6)$ & $\mathrm{Cu}(2)-\mathrm{O}(9)$ & $1.932(6)$ \\
\hline Dy (1)-O(14) & $2.368(6)$ & $\mathrm{Cu}(2)-\mathrm{O}(10)$ & $1.938(6)$ \\
\hline Dy (1)-O(15) & $2.298(5)$ & $\mathrm{Cu}(3)-\mathrm{O}(4)$ & $2.604(6)$ \\
\hline Dy (1)-O(16) & $2.374(5)$ & $\mathrm{Cu}(3)-\mathrm{O}(4) \# 1$ & $2.604(6)$ \\
\hline Dy (1)-O(17) & $2.306(6)$ & $\mathrm{Cu}(3)-\mathrm{O}(11)$ & $1.939(6)$ \\
\hline Dy (1)-O(18) & $2.374(5)$ & $\mathrm{Cu}(3)-\mathrm{O}(12)$ & $1.922(6)$ \\
\hline $\mathrm{Cu}(1)-\mathrm{N}(1)$ & $2.038(7)$ & $\mathrm{O}(1)-\mathrm{N}(2)$ & $1.259(9)$ \\
\hline $\mathrm{Cu}(1)-\mathrm{O}(5)$ & $1.995(7)$ & $\mathrm{O}(2)-\mathrm{N}(3)$ & $1.304(8)$ \\
\hline $\mathrm{Cu}(1)-\mathrm{O}(6)$ & $1.935(6)$ & $\mathrm{O}(3)-\mathrm{N}(4)$ & $1.293(8)$ \\
\hline $\mathrm{Cu}(1)-\mathrm{O}(7)$ & $2.129(6)$ & $\mathrm{O}(4)-\mathrm{N}(5)$ & $1.268(9)$ \\
\hline $\mathrm{Cu}(1)-\mathrm{O}(8)$ & $1.943(6)$ & & \\
\hline \multicolumn{4}{|l|}{ Angles } \\
\hline$O(2)-D y(1)-O(3)$ & $82.4(7)$ & $\mathrm{O}(1)-\mathrm{Cu}(2)-\mathrm{O}(1) \# 1$ & 180.0 \\
\hline$O(13)-D y(1)-O(2)$ & $115.9(2)$ & $\mathrm{O}(9) \# 1-\mathrm{Cu}(2)-\mathrm{O}(9)$ & 180.0 \\
\hline$O(13)-D y(1)-O(3)$ & $71.3(1)$ & $\mathrm{O}(10) \# 1-\mathrm{Cu}(2)-\mathrm{O}(10)$ & 180.0 \\
\hline$O(15)-D y(1)-O(2)$ & $146.3(2)$ & $\mathrm{O}(10)-\mathrm{Cu}(2)-\mathrm{O}(1)$ & $98.3(3)$ \\
\hline$O(15)-D y(1)-O(3)$ & $83.6(2)$ & $\mathrm{O}(10)-\mathrm{Cu}(2)-\mathrm{O}(1) \# 1$ & $81.7(3)$ \\
\hline$O(17)-D y(1)-O(2)$ & $84.0(2)$ & $\mathrm{O}(4)-\mathrm{Cu}(3)-\mathrm{O}(4) \# 1$ & 180.0 \\
\hline$O(17)-D y(1)-O(3)$ & $142.8(3)$ & $\mathrm{O}(11)-\mathrm{Cu}(3)-\mathrm{O}(11) \# 2$ & 180.0 \\
\hline $\mathrm{O}(5)-\mathrm{Cu}(1)-\mathrm{O}(6)$ & $90.9(3)$ & $\mathrm{O}(12)-\mathrm{Cu}(3)-\mathrm{O}(12) \# 2$ & 180.0 \\
\hline $\mathrm{O}(7)-\mathrm{Cu}(1)-\mathrm{O}(8)$ & $89.7(2)$ & $N(3)-O(2)-D y(1)$ & $136.6(5)$ \\
\hline $\mathrm{O}(5)-\mathrm{Cu}(1)-\mathrm{N}(1)$ & $144.2(3)$ & $N(4)-O(3)-D y(1)$ & $138.7(4)$ \\
\hline $\mathrm{O}(6)-\mathrm{Cu}(1)-\mathrm{N}(1)$ & $93.1(3)$ & $N(2)-O(1)-C u(2)$ & $147.3(7)$ \\
\hline $\mathrm{O}(7)-\mathrm{Cu}(1)-\mathrm{N}(1)$ & $108.4(3)$ & $\mathrm{N}(5)-\mathrm{O}(4)-\mathrm{Cu}(3)$ & $144.4(5)$ \\
\hline $\mathrm{O}(8)-\mathrm{Cu}(1)-\mathrm{N}(1)$ & $92.6(3)$ & & \\
\hline
\end{tabular}

Symmetry transformations used to generate equivalent atoms: $\# 1-x, y,-z+1 / 2 ; \# 2-x+1, y,-z+1 / 2$ 


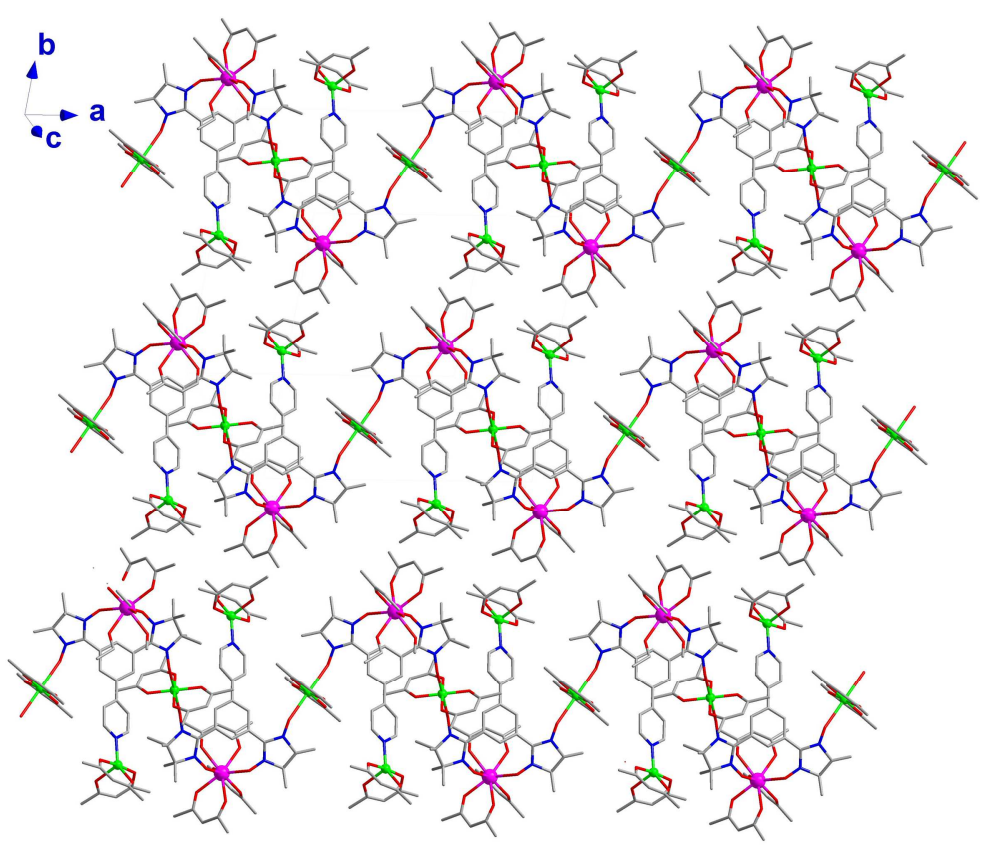

Fig S1. Packing diagram of complex 1. All H, F atoms are omitted for clarity.
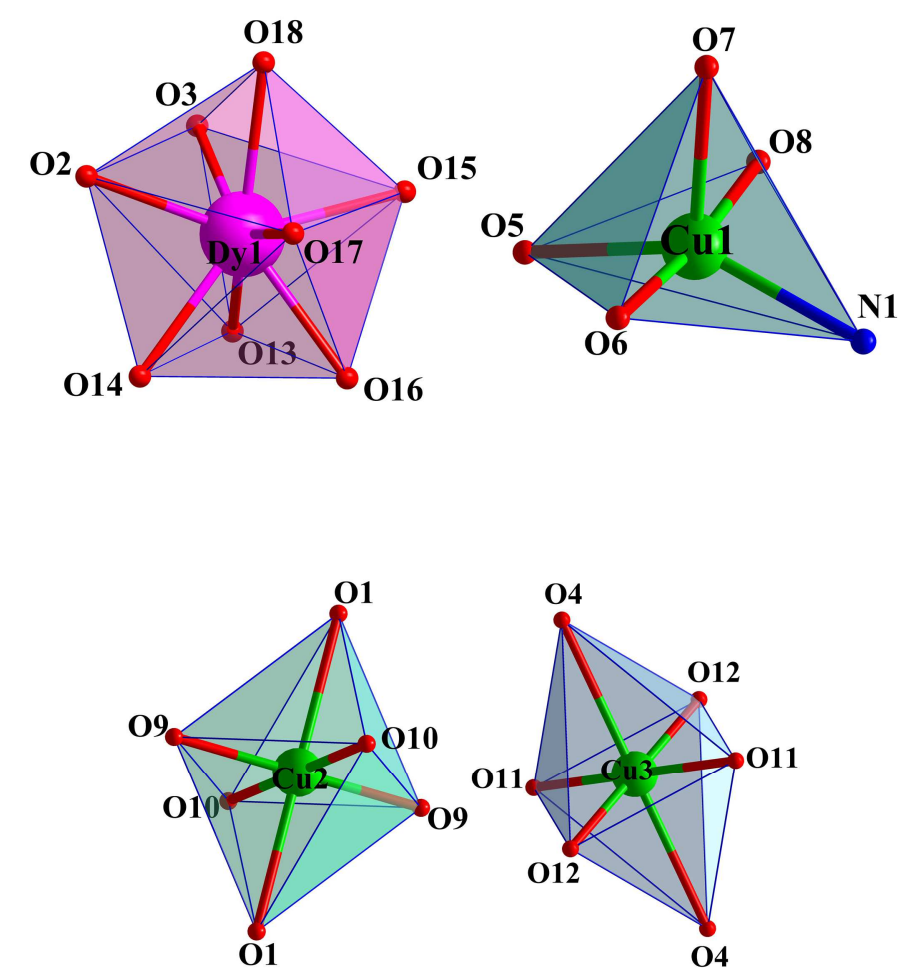

Fig S2. Coordination polyhedron of the $\mathrm{Dy}^{\prime \prime \prime}, \mathrm{Cu}^{\prime \prime} 1, \mathrm{Cu}^{\prime \prime} 2$ and $\mathrm{Cu}^{\prime \prime} 3$ ions. 
Table S3. Detailed geometry analysis results by Continuous Shape Measures

\begin{tabular}{lccccc}
\hline Compound & SAPR-8 & TDD-8 & JBTPR-8 & BTPR-8 & JSD-8 \\
\hline 1Dy & 2.074 & 1.879 & 1.489 & $\mathbf{0 . 7 4 3}$ & 3.658
\end{tabular}

SAPR-8: square antiprism. TDD-8: triangular dodecahedron. JBTPR-8 : Biaugmented trigonal prism J50. BTPR-8: biaugmented trigonal prism. JSD-8 : Snub diphenoid J84

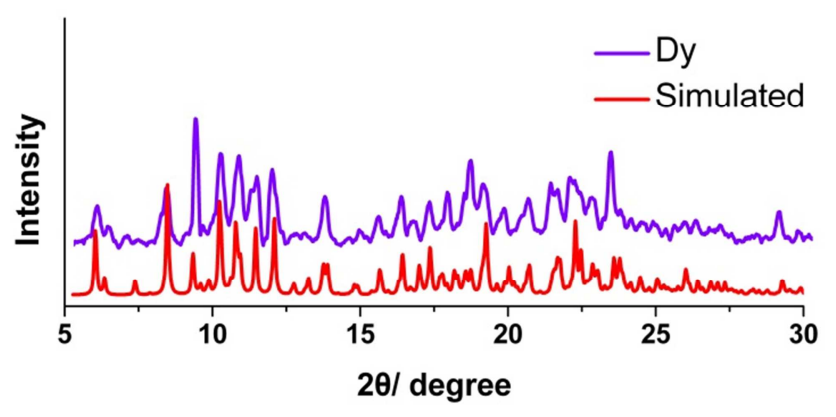

Fig. S3 Powder X-ray diffraction pattern of Dy complex at $293 \mathrm{~K}$, together with the calculated pattern from the crystal structure data. 


\section{Magnetic measurements}
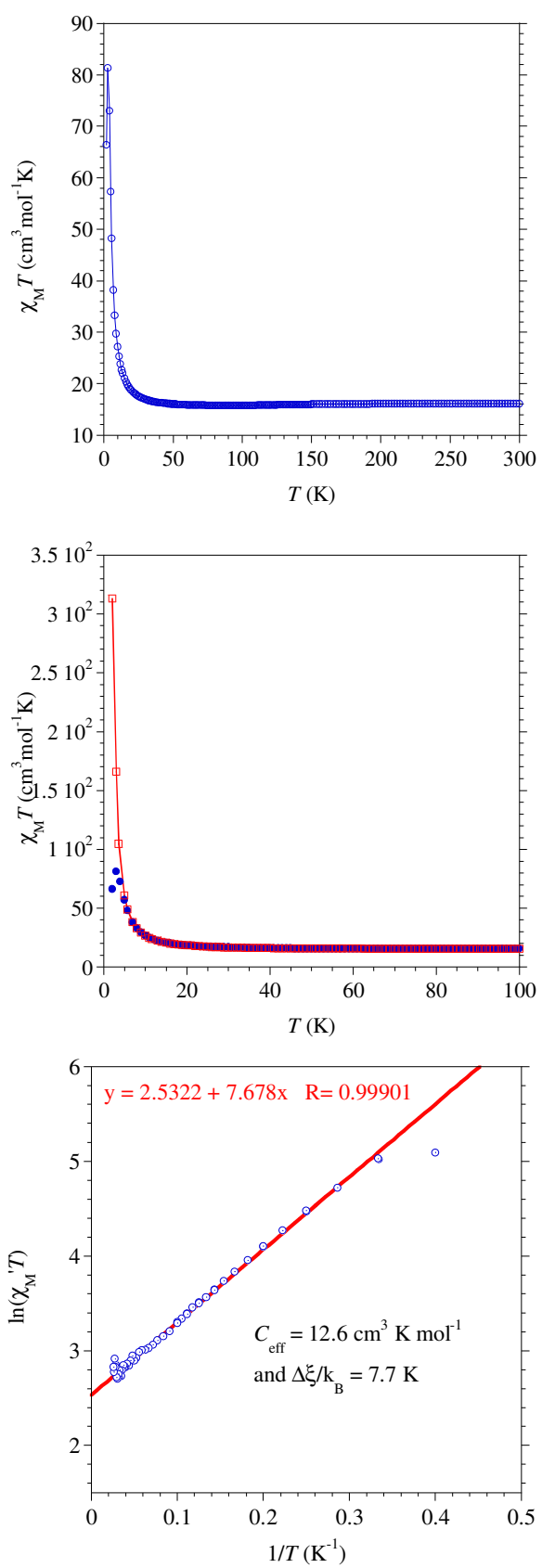

Figure SI4. Temperature dependence of $\chi_{M} T$ with $\chi_{M}$ (top) recorded in an applied field of $1 \mathrm{kOe},\left(\right.$ middle) variation of $\chi_{\mathrm{M}} T$ below $100 \mathrm{~K}$ in an applied field of 50 Oe (in red) and $1 \mathrm{kOe}$ (blue) revealing a saturation effect in larger field; and, (bottom) $\ln \left(\chi_{M}{ }^{\prime} T\right)=f\left(T^{-1}\right)$ $\left(\chi_{M}{ }^{\prime}\right.$, the in-phase susceptibility measured with an AC field of $3 \mathrm{Oe}(v=100 \mathrm{~Hz})$ in the absence of a dc field), the solid red line is the best fit of the Glauber's expression to the linear part between 3 and $25 \mathrm{~K}$. 

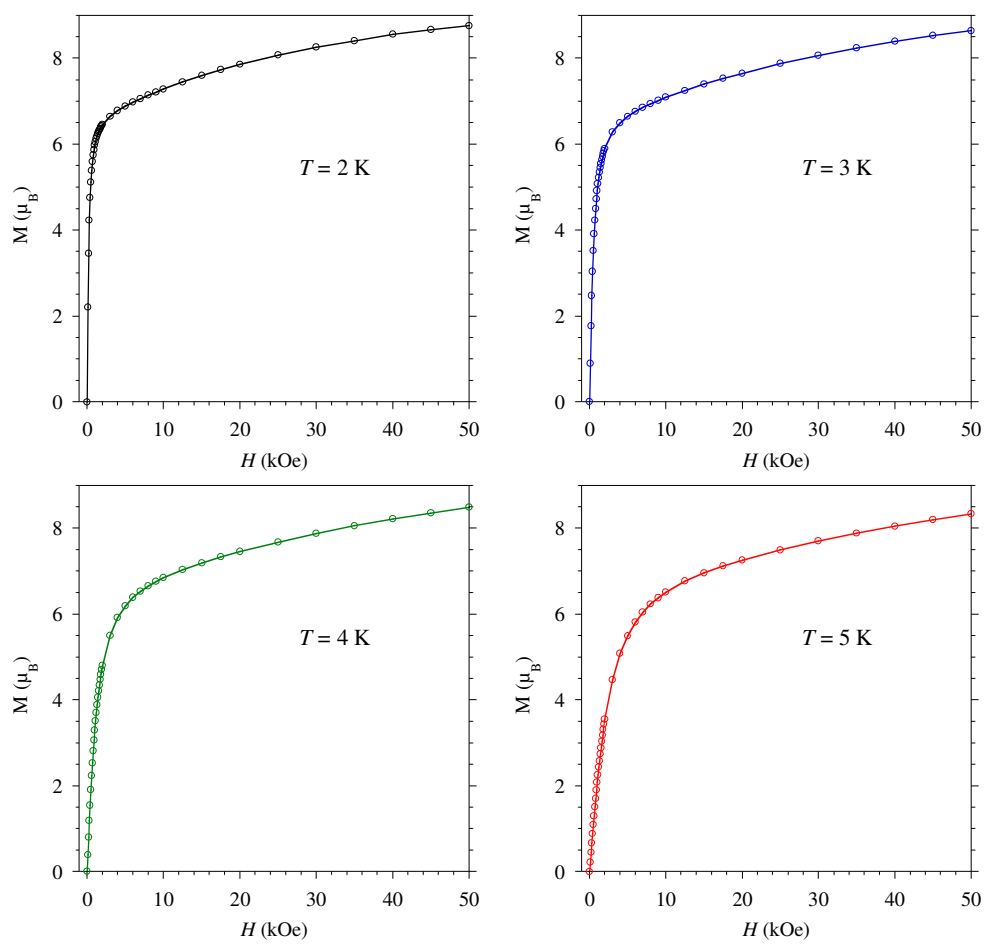

Figure S5. Field dependence of the magnetization at different temperatures for 1. 


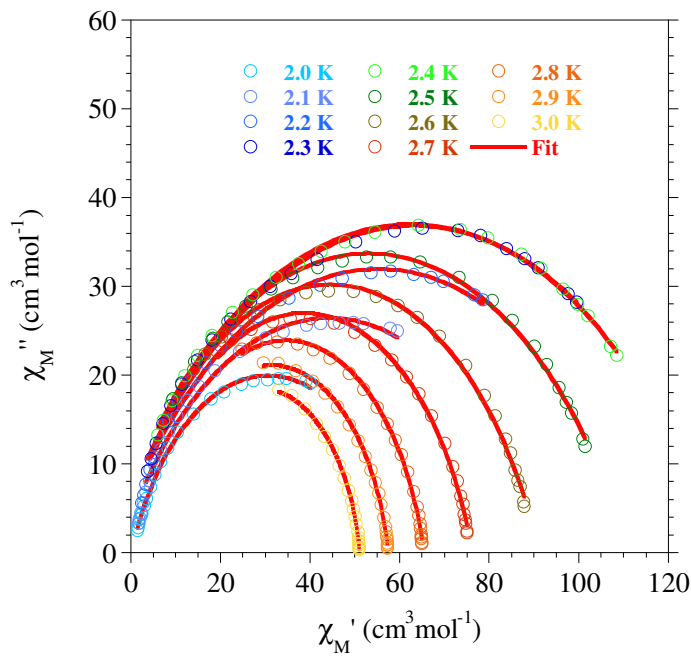

\begin{tabular}{|c|c|c|c|}
\hline$T(K)$ & $X_{\text {iso }}$ & $\mathbf{X}_{\text {adia }}$ & $\alpha$ \\
\hline 2.0 & 61 & 0.1 & 0.26 \\
\hline 2.1 & 91 & -2 & 0.34 \\
\hline 2.2 & 115 & -4.2 & 0.37 \\
\hline 2.3 & 131 & -4.4 & 0.36 \\
\hline 2.4 & 130 & -5.5 & 0.36 \\
\hline 2.5 & 111 & -4.7 & 0.32 \\
\hline 2.6 & 91 & -2.1 & 0.27 \\
\hline 2.7 & 76.2 & 1.1 & 0.20 \\
\hline 2.8 & 65.5 & 3.8 & 0.16 \\
\hline 2.9 & 57.5 & 5.6 & 0.13 \\
\hline 3.0 & 51.1 & 7.2 & 0.11 \\
\hline
\end{tabular}

Figure S6. $\chi_{M}{ }^{\prime}=f\left(\chi_{M}{ }^{\prime \prime}\right)$, i.e. Cole-Cole plots and best fits (solid lines) with a generalized Debye model, the fit parameters are gathered in the table.

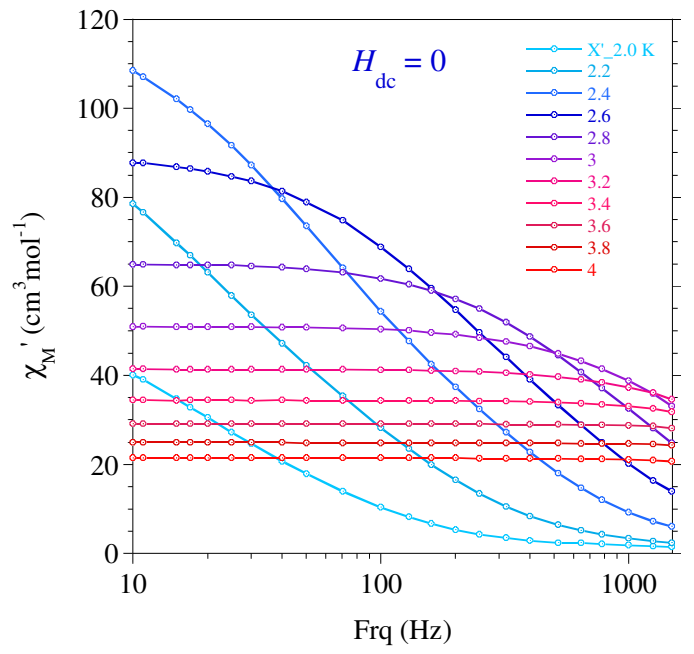

Figure S7. Frequency-dependent out-of-phase signals ( $\left.\chi^{\prime \prime}\right)$ for 1 under zero dc field with $H_{\mathrm{AC}}=3 \mathrm{Oe}$ 


\section{References}

[S1]. H. D. Li, J. Sun, M. Yang, Z. Sun, J. K. Tang, Y. Ma, L. C. Li., Inorg. Chem. 2018, 57, 97579765.

[S2].Sheldrick, G. M. SADABS, Program for Absorption Correction of Area Detector Frames, BRUKER AXS Inc., Madison, WI.

[S3].Sheldrick, G. M. SHELXS-2014, Program for structure solution; Universitat Gottingen: Gottingen, Germany, 2014. 